\title{
Switching Off Mentally: Predictors and Consequences of Psychological Detachment From Work During Off-Job Time
}

\author{
Sabine Sonnentag and Ute-Vera Bayer \\ University of Konstanz
}

\begin{abstract}
Psychological detachment from work refers to the off-job experience of "switching off" mentally. It is hypothesized that a high degree of workload encountered during the work day has a negative impact on subsequent detachment processes and that psychological detachment from work is positively related to well-being. Eighty-seven individuals from various occupations provided questionnaire and daily survey measures over a period of 3 working days. Multilevel analysis showed that workload was negatively related to psychological detachment from work during evening hours. Psychological detachment from work was associated with positive mood and low fatigue. The negative relationship between psychological detachment and fatigue was particularly strong on days with high time pressure.
\end{abstract}

Keywords: job stress, overload, psychological detachment, recovery, well-being

Literally hundreds of studies have shown that stressful work situations are associated with poor individual well-being and increased health risks (for reviews, cf. Ganster \& Schaubroeck, 1991; Kahn \& Byosiere, 1992; Sonnentag \& Frese, 2003). Particularly, high workload was found to be related to impaired health and well-being (Sparks, Cooper, Fried, \& Shirom, 1997; Van der Doef \& Maes, 1999).

In addition, researchers have argued that the inability to rest and recover from work might have severe negative effects on individual health and wellbeing (Eden, 2001; Lundberg \& Lindfors, 2002; McEwen, 1998; Meijman \& Mulder, 1998). Empirical research has shown that insufficient recovery is associated with poor psychological and physical health, such as psychosomatic complaints and burnout (Elfering, Grebner, Semmer, \& Gerber, 2002; Sluiter, Van der Beek, \& Frings-Dresen, 1999). Moreover, research evidence suggests that individuals' well-being and work behavior benefit from respite time during evening hours (Sonnentag, 2001, 2003) as well as from longer respite periods such as vacations (Westman \& Eden, 1997; Westman \& Etzion, 2001). It seems, however, that it is not merely the amount of the time available for respite and recovery that matters; the quality of the respite ex-

Sabine Sonnentag and Ute-Vera Bayer, Department of Psychology, University of Konstanz, Konstanz, Germany.

Correspondence concerning this article should be addressed to Sabine Sonnentag, Department of Psychology, University of Konstanz, Postbox D42, Konstanz D-78457, Germany. E-mail: sabine.sonnentag@uni-konstanz.de perience also plays an important role in the recovery process (Etzion, Eden, \& Lapidot, 1998; Lounsbury \& Hoopes, 1986; Westman \& Eden, 1997).

Eden (2001) suggested that psychological detachment from work, that is, not thinking of one's work during off-job time, should be a core factor in future respite research. Psychological detachment from work has been shown to be one of the major factors that contribute to the improvement of well-being during longer respite periods (Etzion et al., 1998). Until now, researchers have focused on psychological detachment during relatively long respite periods, such as those lasting 2 weeks or longer (Etzion et al., 1998). To our knowledge, short-term psychological detachment from work, such as that occurring during the evenings of normal work weeks, has not yet been investigated. Moreover, it is largely unclear which factors support or hinder psychological detachment from work.

There are at least two reasons why it is important to extend research on psychological detachment to shorter time intervals. First, the effects of longer respites (e.g., vacations) fade out relatively quickly (Fritz \& Sonnentag, in press; Westman \& Eden, 1997); therefore, it is useful to investigate which factors help in maintaining well-being in between these periods. Second, if individuals do not recover sufficiently within shorter time intervals, strain reactions may accumulate and result in severe impairments of health and well-being (Meijman \& Mulder, 1998). Therefore, it is crucial to examine the antecedents and potential benefits of short-term detachment from work. 
In this article, we examine short-term psychological detachment from work occurring during the evenings of normal work weeks. We pursued two specific goals: First, we were interested in the relationship between work-situation variables, particularly quantitative workload and psychological detachment. Second, we examined whether psychological detachment from work during evening hours helps in improving well-being after work. Figure 1 displays the conceptual model that we tested in this study. We propose that the degree of psychological detachment from work is negatively affected by a person's quantitative workload, even when controlling for individual differences such as action-state orientation (Kuhl, 1994b) that might be related to psychological detachment. In addition, we propose that psychological detachment from work has an effect on well-being at bedtime, even after taking into

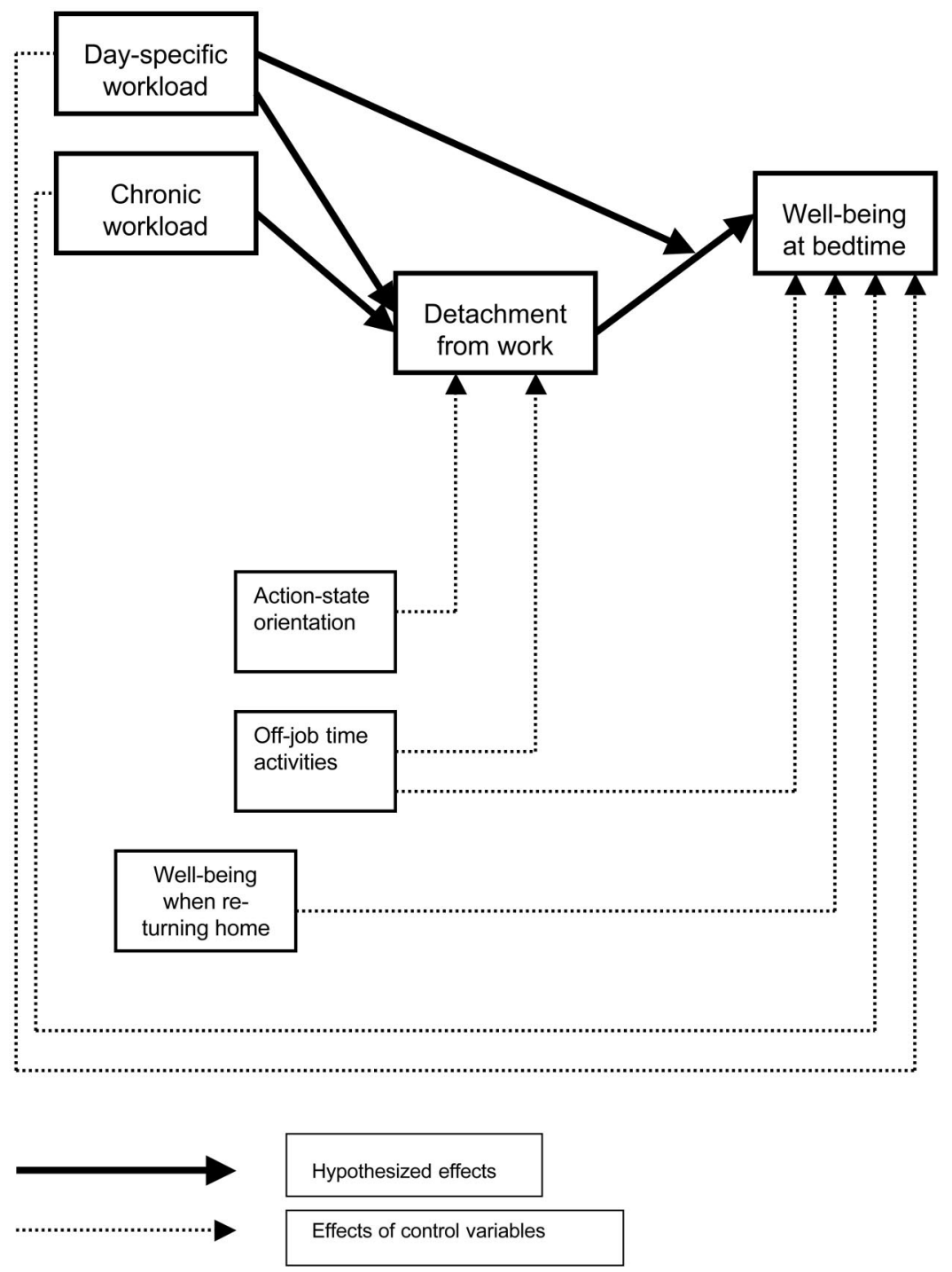

Figure 1. Conceptual model. Solid lines represent hypothesized relationships and dotted lines show potential effects of control variables included in the analyses. 
account workload, time spent on specific off-job activities, and well-being when returning home from work. More specifically, on the basis of well-known models of affect (Russell, 1980; Watson \& Tellegen, 1985), we were interested both in pleasure (positive mood) and displeasure (negative mood) as aspects of well-being. With respect to negative mood, we particularly focused on low arousal (cf. Russell, 1980) and examined fatigue as an aspect of displeasure that is highly relevant in the context of job-related disturbances of well-being (deCroon, Sluiter, Blonk, Broersen, \& Frings-Dresen, 2004).

We focus on well-being at bedtime as a core outcome variable for several reasons. First, the question of how job-related factors affect individuals' functioning and experiences off the job is an important topic within occupational health psychology and related fields (Adams, King, \& King, 1996; Hart, 1999; Rothbard, 2001). Second, impaired well-being does not disappear from one day to the next but tends to spill over into subsequent working days (Totterdell, Spelten, Smith, Barton, \& Folkard, 1995). In addition, an individual's well-being at bedtime has an impact on sleep quality and sleep efficiency (Morin, Rodrigue, \& Ivers, 2003), which in turn affects jobrelated behavior during the subsequent day (Krueger, 1989).

Because one can assume that the degree of psychological detachment differs substantially from day to day, we are mainly interested in the predictors and consequences of day-specific levels of psychological detachment. Therefore, we examined not only between-person effects but also within-person variations of workload, psychological detachment, positive mood, and fatigue. Other aspects of well-being that might be also affected by low psychological detachment, but that develop within a longer time frame (e.g., health complaints, job satisfaction, life satisfaction), were beyond the scope of the present study.

\section{Psychological Detachment Concept}

In traditional working arrangements of the past, most individuals not working at home had the opportunity to detach themselves from work during off-job time. They physically left their working place and went home or to other places where they spent their evening hours or weekends. However, nowadays, being physically away from the working place does not necessarily imply leaving one's work behind in psychological terms. In modern work contexts, individuals have to focus on getting their work done, regardless of the location at which they complete their tasks. For example, while at home, individuals may have to accomplish additional job-related tasks such as reading reports or preparing material for the next working day. In addition, when not deliberately accomplishing job-related tasks, individuals may continue to think about their jobs, ruminate about job-related problems, or reflect about future opportunities. When staying psychologically attached to their jobs during evening hours, individuals may not fully benefit from their off-job time.

Etzion et al. (1998) introduced the term sense of detachment for describing "the individual's sense of being away from the work situation" (p. 579). Detachment implies not being occupied by work-related duties. For example, when detached from work, an individual will not receive job-related phone calls at home and will refrain from job-related activities. In addition, detachment involves disengaging oneself psychologically from work. When psychologically detached from work, one stops thinking of or ruminating about job-related problems or opportunities. In this article, we use the term psychological detachment to emphasize the psychological component of disengaging from work during off-job time-as opposed to being simply physically absent from the workplace. Psychological detachment implies a distraction from job-related thoughts. For psychological detachment to occur, it is not sufficient for one to change location by leaving the working place; one must also take a break from thinking about workrelated issues.

\section{Predictors of Psychological Detachment}

We propose that job-related factors, particularly quantitative workload, are related to the inability to psychologically detach from work during evening hours. Quantitative workload refers to a high amount of work and implies that an individual has too much to do in too little time. Workload is experienced as time pressure and is often dealt with by working faster or by working longer hours (Major, Klein, \& Ehrhart, 2002). There is evidence from longitudinal research that high workload is one of the core jobrelated predictors of poor health and well-being (Carayon, 1993; Ganster, Fox, \& Dwyer, 2001; Spector, Chen, \& O'Connell, 2000). Moreover, research has shown that quantitative workload has an impact on individuals' functioning within nonwork domains. For example, after having faced high workload during the day, physiological unwinding after work is prolonged (Frankenhaeuser, 1981; Meijman, Mulder, 
Van Dormolen, \& Cremer, 1992). In addition, high workload is associated with the experience of workfamily conflict (Geurts \& Demerouti, 2003). Thus, workload is an aspect of the work situation that spills over into the nonwork domain and continues its influence on the individual after the end of the working day. Therefore, it is likely that workload also hinders psychological detachment from work during evening hours.

Recently, Geurts, Kompier, Roxburgh, and Houtman (2003) argued that high workload negatively affects health and well-being because it limits the opportunities for recovery. More specifically, we assume that high workload makes psychological detachment from work less likely. When looking at the effects of workload on psychological detachment from a daily perspective, one can differentiate between chronic and day-specific workload. Chronic workload refers to the more permanent level of workload that is present every day, whereas day-specific workload refers to the degree of workload present on the particular day. For example, it might be that in a given job chronic workload is relatively low but that from time to time day-specific workload becomes extremely high.

There are several reasons for the proposed negative effect of chronic and day-specific workload on psychological detachment. First, when confronted with high chronic or day-specific workload, individuals may be more inclined to take some work home and continue to work on job-related tasks. By definition, they cannot detach from work while they are busy with job-related duties. In addition, even when not actually working they may not detach because they might anticipate having to do something later in the evening or because work material is still around despite the individual having finished the task.

Second, even when not taking work home and not deliberately accomplishing job-related tasks at home, it might be difficult to detach psychologically from work in the evening when facing a high chronic or a high day-specific workload. Compared with a lowworkload situation, the likelihood of not having finished all tasks when leaving the workplace in the evening might be higher when working under a high workload. Awareness that not all tasks have been finished might make it difficult to detach from work.

Third, particularly when high workload is not a single event but continues for longer time, as in the case of high chronic workload, individuals might also anticipate a high workload for the next working day. As a consequence they possibly worry about how to manage all the tasks that must be accomplished dur- ing the following day. Therefore, psychological detachment might be difficult. We proposed the following:

Hypothesis 1: Chronic and day-specific workload will be negatively related to psychological detachment from work during evening hours.

\section{Consequences of Psychological Detachment}

We assumed that psychological detachment from work plays a core role in recovery processes, and therefore we proposed that it would have a positive effect on well-being. Recovery can be conceptualized as a process opposite to the strain process that has been caused by exposure to stressors. In other words, recovery eliminates-or at least alleviates-the mood and performance-related effects of stressors and restores individual well-being and performance potential. As a result, an individual's functioning returns to its prestressor level (Craig \& Cooper, 1992; Meijman \& Mulder, 1998). Recovery from workrelated strain and its associated improvement of mood requires that work stressors cease to impact on the individual and that no further demands are put on the resources that were called upon during the work process (Craig \& Cooper, 1992; Meijman \& Mulder, 1998). In simple terms, the probability to recover will be low if a person continues to pursue job-related activities during off-job time (Sonnentag, 2001). Still, the type of activity pursued is not the only factor relevant for the onset of recovery processes. We assume that psychological detachment from work is crucial for recovery to occur. For example, imagine an individual watching a TV program but at the same time thinking about an unfinished work task or worrying about how to cope with a high workload anticipated for the next working days to come. In this situation, the likelihood of recovery will be low because the resources needed at work are continuously called upon during off-job time.

Research on mood regulation emphasizes the importance of detachment and distraction for mood improvement. In everyday situations, individuals regard engagement in pleasant distraction from negative experiences and from bad mood as a highly successful strategy for mood regulation (Thayer, Newman, \& McClain, 1994). Totterdell and Parkinson (1999) investigated the actual effects of different mood regulation strategies. They found that participants' mood improved after doing something distracting. Rumination about job-related issues may be seen as an extreme form of not psychologically de- 
taching from work in evening hours. Experimental research has shown that distraction reduces depressed mood in normally nondepressed persons, whereas rumination results in an increase of depressed mood (Morrow \& Nolen-Hoeksema, 1990). Moreover, rumination was found to be positively related to other strain indicators, such as feelings of nervousness and elevated levels of cortisol (Roger \& Najarian, 1998; Young \& Nolen-Hoeksema, 2001). On the basis of theoretical work about recovery processes and empirical research on mood regulation, we proposed that psychological detachment from work during evening hours improves well-being at bedtime:

Hypothesis 2: Psychological detachment from work during evening hours will be positively related to well-being at bedtime.

Psychological detachment might not be not equally important in all situations, though. For example, when facing a highly stressful work situation during the day, psychological detachment during the evening might be particularly needed in order to recover and restore one's well-being. When continuing to think about work-related issues after a stressful working day, the likelihood might be high that one's thoughts refer to stressful events. As a consequence, well-being will suffer. However, after a less stressful working day, job-related thoughts during the evening might be less negative. Therefore, the relationship between psychological detachment and well-being will be weaker. One might even argue that after a highly successful and enjoyable working day the relationship between low psychological detachment (i.e., continuing to think about the positive events encountered during the day) and well-being will be positive. More specifically, with respect to workload as a core stressor we proposed that the relationship between lack of psychological detachment and poor well-being would be strong after a high-workload day because after such a day strain reactions would be particularly high (Teuchmann, Totterdell, \& Parker, 1999). To successfully regulate one's wellbeing during the evening of a high-workload day, it is particularly important to psychologically detach from work, that is to stop thinking about the very situation that caused the strain (Totterdell \& Parkinson, 1999). If one continues to think about work during such an evening, it is likely that thinking about work will be characterized by highly stressful thoughts that in turn are negatively related to one's well-being. In case of low day-specific workload however, work-related thoughts during evening hours-if they occur- might be less stressful and more positive. In such a situation, refraining from work-related thoughts will not be so crucial for one's well-being. We made the following hypothesis:

Hypothesis 3: Day-specific workload moderates the relationship between psychological detachment during evening hours and well-being at bedtime. Psychological detachment will be more strongly associated with well-being on days with high day-specific workload than on days with low day-specific workload.

\section{Control Variables}

When analyzing the effects of psychological detachment on well-being one has to take into account that not only psychological detachment from work experienced during evening hours but also a range of other variables might affect well-being at bedtime. For example, well-being at bedtime might be also affected by well-being when coming home from work or from the level of workload experienced during the work day (Frankenhaeuser, 1981; Meijman et al., 1992). Also, off-job time activities pursued during the evening might have an impact on well-being at bedtime (Sonnentag, 2001). To rule out these alternative interpretations, we controlled for workload, time spent on off-job time activities, and previous well-being when analyzing the effects of psychological detachment on well-being at bedtime.

With respect to the prediction of psychological detachment from work, there might be individual difference variables that account for variance in an individual's ability to detach from work. We assume that action-state orientation (Kuhl, 1994b) is a key variable when it comes to individual differences in psychological detachment from work. Action-oriented individuals are able to allocate their attention to the present situation and the task at hand, whereas state-oriented individuals tend to ruminate about past situations and failures. To examine the effects of quantitative workload above and beyond the effects of more dispositional factors, we controlled for action-state orientation when predicting psychological detachment from work.

In addition, psychological detachment from work might depend not only on job-related and individualdifference factors but also on off-job factors. The types of activities an individual pursues and the time he or she spends on them are crucial for psychological detachment to occur. For example, spending a high amount time on job-related activities during 
evening hours might be negatively related to psychological detachment. Spending much time on activities that are not job-related might increase the likelihood of detaching psychologically from work. Moreover, individuals facing a high workload might choose other off-job activities to detach-or to continue thinking about work - than might individuals facing less workload. To investigate the effect of workload on psychological detachment above and beyond the effects of off-job activities, we controlled for the types of activities individuals pursued during off-job time.

Also demographic variables such as age, gender, and number of children might have an effect on psychological detachment from work and on wellbeing. Therefore, we controlled for age, gender, and number of children in the analyses.

\section{Method}

\section{Sample and Procedure}

To recruit participants, we contacted the personnel departments of 10 organizations (7 private organizations and 3 public service organizations) as well as self-employed individuals. These organizations and self-employed individuals produced and delivered a broad range of different goods and services including computer software, pharmaceutical products, consultancy services, distribution services, and public services. We approached these organizations and self-employed individuals because they were known to offer or hold demanding jobs. In addition, these organizations were expected to be interested in employee health and well-being issues. After the managers of all 10 organizations and self-employed individuals expressed interest in the study and agreed that at least one department within the organization was willing to participate, we directly contacted employees and self-employed individuals through personal meetings, mostly held within the organizations. We introduced the study as an investigation on work and recovery, explained the procedure of the study, and solicited participation by emphasizing the relevance of the research topic and by assuring anonymity and confidentiality of all responses. Through these meetings, we distributed 142 survey packages to the potential participants. Each survey package included a letter describing the purpose of the study, a questionnaire, and daily survey material. All items were in German.

Of the 142 survey packages distributed, 97 were returned, representing a response rate of $68 \%$. Ten of these returned survey packages were not usable because of missing data on core person-level variables, leaving a total of 87 completed questionnaires and daily surveys for data analysis (final response rate: $61 \%$ ).

The mean age of participants was 41.6 years $(S D=9.7)$. Fifty-three percent of participants in the sample were men, whereas $47 \%$ were women. Participants came from a broad range of professional backgrounds. Thirty-six percent of the participants held a supervisory position. Five participants
$(5.7 \%)$ were self-employed. On average, participants were highly educated. Fifty-nine percent of the sample had a university degree, $19 \%$ had completed a technical college or a craftsman's diploma, and $18 \%$ had completed an apprenticeship program; only $5 \%$ of the sample had no formal educational degree beyond required school.

The majority of the participants (74.7\%) lived with a partner, whereas $25.3 \%$ lived alone. Some participants (3.4\%) lived as single parents with their children or lived with another person besides a partner or a child. In total, $47 \%$ of the participants had no children, $17 \%$ had one child, $28 \%$ had two children, and $8 \%$ had three or more children.

\section{Questionnaire Measures}

Our data collection procedure was based on questionnaire and daily survey measures. Participants had to complete the questionnaire before they started to fill in the daily survey. We used the questionnaire to assess chronic workload and control variables at the person level. An overview of all questionnaire measures is given in the upper part of Table 1.

Chronic workload. We assessed hours of work and time pressure as aspects of chronic quantitative workload. Specifically, participants reported their chronic work hours by responding to an item in the questionnaire ("How many hours per week do you actually work for your job?"). Chronic time pressure was measured with five 5-point Likert items $(1=$ very seldomly/never to $5=$ very often $)$ from the time pressure scale developed by Semmer (1984) and Zapf (1993), a measure that is often used in German speaking countries for assessing quantitative workload (Frese, 1985; Garst, Frese, \& Molenaar, 2000; Semmer, Zapf, \& Greif, 1996; Cronbach's $\alpha=.79$ ). A sample item was "How often do you work under time pressure?"

Control variables at the person level. We assessed participants' gender, age, and number of children with single items. We measured action-state orientation with the 12item preoccupation subscale of the Action Control Scale (ACS-90; Kuhl, 1990, 1994a). A sample item was "If I've worked for four weeks on one project and then everything goes completely wrong with it: (a) It takes me a long time to adjust myself to it. (b) It bothers me for a while, but then I don't think about it any more," with (a) indicating a state-oriented answer and (b) indicating an action-oriented answer. Cronbach's alpha was .73. Items were scored such that a high score represented high action orientation.

\section{Daily Survey Measures}

The daily survey had to be completed over a period of 3 consecutive work days. On each day, participants were asked to respond to items on two measurement occasions: (a) when returning home from work and (b) before going to bed. We decided to use self-paced daily survey materials-as opposed to beepers-because participants' working and sleeping times differed largely from person to person and from day to day. To avoid the possibility that the process of completing the daily survey affected the participants' well-being, we asked participants to complete, on all days at both measurement occasions, well-being items first and then the other daily survey items. The lower part of Table 1 gives an overview over all daily survey measures. 
Table 1

Overview Over Measures

\begin{tabular}{|c|c|c|c|}
\hline Construct & Instrument & $\begin{array}{l}\text { Frequency of } \\
\text { assessment }\end{array}$ & Time of assessment \\
\hline Chronic time pressure & Questionnaire & Once & \\
\hline Chronic work hours & Questionnaire & Once & \\
\hline Action-state orientation & Questionnaire & Once & \\
\hline Demographic variables: gender, age, no. of children & Questionnaire & Once & \\
\hline Day-specific time pressure & Daily survey & 3 days & Upon return from work \\
\hline Day-specific work hours & Daily survey & 3 days & Upon return from work \\
\hline Positive mood when returning home & Daily survey & 3 days & Upon return from work \\
\hline Fatigue when returning home & Daily survey & 3 days & Upon return from work \\
\hline Psychological detachment & Daily survey & 3 days & At bedtime \\
\hline Positive mood at bedtime & Daily survey & 3 days & At bedtime \\
\hline Fatigue at bedtime & Daily survey & 3 days & At bedtime \\
\hline Time spent on work-related activities & Daily survey & 3 days & At bedtime \\
\hline Time spent on household and child-care activities & Daily survey & 3 days & At bedtime \\
\hline Time spent on low-effort activities & Daily survey & 3 days & At bedtime \\
\hline Time spent on social activities & Daily survey & 3 days & At bedtime \\
\hline Time spent on physical activities & Daily survey & 3 days & At bedtime \\
\hline
\end{tabular}

Day-specific workload. In addition to chronic workload assessed with the questionnaire, we measured day-specific workload with the daily survey on each day at the first measurement occasion, that is, when returning home from work. Specifically, participants indicated their day-specific work hours by responding to the question "How many hours did you work today?" For measuring day-specific time pressure, we adapted three items from Semmer's (1984) and Zapf's (1993) time pressure scale. Specifically, we formulated the items in a way that they applied to the situation on the specific day (e.g., "Today I had to work under time pressure"). Participants responded to these items on a 5 -point Likert scale $(1=$ not true at all to $5=$ very true $)$. We used this subset of three items instead of the full version for economical reasons. Cronbach's alphas computed separately for the 3 days ranged between .89 and .91 .

Well-being when returning home from work. We assessed well-being when returning home from work in the daily survey at the first measurement occasion, immediately after participants returned home from work. More specifically, we measured positive mood and fatigue with measures developed by Nitsch (1976). These measures assess an individual's present state and are widely used in Germanspeaking countries for measuring mood states in various life domains. Research has demonstrated that these measures show good construct validity and sensitivity to mood changes (Apenburg, 1986; Martin \& Weber, 1976; Udris \& Barth, 1976).

Specifically, on each of the 3 days, participants responded to seven items assessing positive mood ("cheerful," "good humored," "content," "joyous," "hilarious," "carefree," "harmonic") and to five items assessing fatigue ("depleted," "tired out," "in need of recovery," "rested" (recoded), "recreated" (recoded)). Participants were instructed to report with respect to every adjective how they felt "now, at this moment, after work." Participants provided their responses on 6-point Likert scales ranging from $1=$ barely to $6=$ completely. Cronbach's alphas computed separately for the
3 days ranged between .91 and .94 for positive mood and between .86 and .89 for fatigue. To examine the distinctiveness of our positive mood and fatigue measures, we performed a set of confirmatory factor analyses. For each of the 3 days, we performed separate analyses in which we compared a one-factor model (with all items loading on one latent factor) with a two-factor model (with all positive mood items loading on a positive mood factor and with all fatigue items loading on a fatigue factor). Although model fit for the two-factor models was not perfect, for all 3 days, the two-factor model fit the data better than did the onefactor model, $\Delta \chi^{2}(1, N=81)>128.54, p<.01$.

Psychological detachment from work. We assessed psychological detachment from work on a daily basis with the daily survey at the second measurement occasion (i.e., each day at bedtime). We asked participants to indicate their level of psychological detachment experienced during five different types of activities performed on the respective day. We used this activity-specific psychological detachment measures to gather more detailed information and because we assessed that the degree of psychological detachment might differ from one activity to another. More specifically, we first gave short descriptions of five activity categories and a list of prototypical activities within each category. These activity categories and related descriptions had been developed in an earlier study (Sonnentag, 2001). The five activity categories were composed of the following: (a) work-related activities (e.g., finishing or preparing for work duties and doing one's private administration such as completing one's tax declaration or paying bills), (b) household and child-care activities (e.g., cooking, doing the dishes, shopping, taking care of the children), (c) low-effort activities (e.g., watching TV, taking a bath), (d) social activities (e.g., meeting with others, making a phone call in order to chat), (e) physical activities (e.g., sports, cycling). For each of these activity categories, participants had to indicate whether they had performed this type of activity on that day. If they answered "yes," they were asked to report the 
amount of time they had spent on the respective category and to respond to three psychological detachment items on a 5 -point Likert scale $(1=$ not true at all to $5=$ very true $)$ : (a) "While performing this activity, I forgot completely about my working day"; (b) "While performing this activity, I could 'switch off' completely"; and (c) "While performing this activity, I had to think about my work again and again" (recoded). If they answered "no" (i.e., if they had not performed the specific type of activity on the respective day), they were asked to proceed to the items referring to the next activity category.

We computed Cronbach's alphas of this psychological detachment measure separately for each of the five activity categories and for each of the 3 days. For work-related activities, Cronbach's alphas computed separately for the 3 days ranged between .74 and .88 . For household and childcare activities, Cronbach's alphas ranged between .72 and .82. For low-effort activities, Cronbach's alphas ranged between .77 and .86. For social activities, Cronbach's alphas ranged between .74 and .91. For physical activities, Cronbach's alphas ranged between .83 and .90 .

To examine the validity of our psychological detachment measure, we compared the degree of psychological detachment experienced during the pursuit of work-related activities with the degree of psychological detachment experienced during the pursuit of other activities. Specifically, for each of the five activity categories, we averaged the psychological detachment scores across the 3 days. If a participant executed an activity on 1 or 2 days only, we based this average psychological detachment score on the data assessed on these single days. Analysis showed that participants experienced less psychological detachment during work-related activities than they did during the other type of activities: household and child-care activities, $t(44)=$ $-4.58, p<.01$; low-effort activities, $t(51)=-8.01, p<$ .01 ; social activities, $t(44)=-5.72 p<.01$; and physical activities, $t(20)=-5.21, p<.01$ (all $t$ tests with Bonferroni adjustment). It is interesting to note that psychological detachment was low during work-related activities, although work-related activities comprised also nonjob activities such as completing one's tax declaration or paying bills. One could expect that the psychological detachment score was even lower when referring only to job-related activities in this category.

Subsequently, we used the day-specific and activity-specific psychological detachment scores to compute overall day-specific psychological detachment measures for each of the 3 days. Specifically, we averaged the psychological detachment score provided for the five activity categories across all activities the person performed on a specific day. This procedure resulted in one psychological detachment score for each participant per day. Very few participants performed all five activities in a single day. Therefore, we could not compute the usual Cronbach's alpha coefficient for these overall day-specific psychological detachment measures. For an indication of the internal consistency of the overall day-specific psychological detachment measures, we correlated the activity-specific psychological detachment measures provided separately for the five activities with the overall day-specific psychological detachment measures. For work-related activities, the correlations between the activity-specific psychological detachment measure and the overall day-specific psychological detachment measure ranged between .63 and .86. For household and child-care activities, the correlations ranged between .64 and .84. For low-effort activities, the correlations ranged between .78 and .83 . For social activities, the correlations ranged between .85 and .88 . For physical activities, they ranged between .60 and .82 . Overall, these correlations correspond to good item-total correlations.

Well-being at bedtime. We assessed well-being at bedtime in the daily survey at the second measurement occasion immediately before the participants went to bed. On each of the 3 days, participants were asked to respond to seven 6-point Likert items measuring positive mood and to five 6-point Likert items measuring fatigue. Specifically, participants were asked to indicate how they felt "now, at this moment, before going to bed." Items were identical to those administered for measuring well-being when returning home from work. Cronbach's alphas computed separately for the 3 days ranged between .93 and .95 for positive mood and between .76 and .83 for fatigue. Again, we conducted a set of confirmatory factor analyses in which we compared a one-factor model with a two-factor model. These analyses showed that for all 3 days, model fit was better for the two-factor model than for the one-factor model, $\Delta \chi^{2}(1, N=$ 81) $>65.96, p<.01$.

One might argue that well-being at bedtime is a rather irrelevant outcome measure because individuals go to sleep anyway. To investigate whether well-being at bedtime matters beyond the specific moment we examined its effect on well-being during subsequent work days. We assessed wellbeing on Day 3 with seven items from the irritation-strain measure developed by Mohr (1986; cf. Frese, 1999; Cronbach's $\alpha=.88)$. Sample item are "Upon returning home from work, I was rather irritated" and "I got angry easily." Participants were instructed to answer the irritation-strain items with respect to how they felt during the past 2 days (i.e., Day 2 and Day 3). Multiple regression analysis showed that positive mood and fatigue at bedtime of Day 1 explained $17 \%$ of the variance in irritation-strain, $F(2,84)=$ $8.661, p<.01$. This result suggests that well-being at bedtime is a relevant predictor of well-being experienced during the subsequent work days.

Control variables at the day level. For control variables at the day level, we assessed the amount of time participants spent on the five types of off-job activities. In the daily survey at the second measurement occasion (i.e., immediately before going to bed), participants reported how much time (in minutes) they had spent on work-related activities, household and child-care activities, low-effort activities, social activities, and physical activities.

\section{Data Analysis Procedure}

For each participant, we gathered data at the person level (e.g., chronic workload, demographic variables) and at the day level (e.g., day-specific workload, psychological detachment, well-being). Day-level data were nested within the person-level data. To analyze our data we used multilevel analysis, also known as hierarchical linear modeling (Bryk \& Raudenbush, 1992). Such a multilevel approach is most appropriate for analyzing hierarchically structured data sets such as the one gathered in the present study. It is superior to ordinary least square regression analysis because it does not require independence of observations but allows for dependent observations within the higher level data 
structure (Snijders \& Bosker, 1999). With respect to the present study, multilevel analysis takes the dependence of day-level data within each person into account.

We used the MLn program for data analysis (Rasbash \& Woodhouse, 1996). In our analyses, predictor variables at the person level (chronic workload, demographic variables) were Level 2 data, and predictor variables at the day level (day-specific workload, off-job time activities, psychological detachment, positive mood and fatigue when returning home) were Level 1 data. We centered person-level predictor variables around the grand mean and day-level predictor variables around the respective person mean. For testing our hypotheses, we followed a hierarchical test procedure and compared a set of nested models. In all sets of analyses we started with a null model that included only the intercept. In the subsequent steps we consecutively added the predictor variables of interest. We tested the improvement of each model with a likelihood ratio statistic. For more information about a similar approach to data analysis, see Sonnentag's (2001) study.

\section{Results}

Table 2 shows means, standard deviations, and zero-order correlations between the study variables. Person-level and day-level correlations are displayed. To correlate variables measured at the day level with variables assessed at the person level, we averaged day-level measures across the 3 days. Day-level variables were not centered before correlating them with other day-level and person-level variables. With respect to person-level correlations, the person was the level of analysis $(N=87)$; with respect to day-level correlations, the day was the level of analysis $(k=$ 221).

Because employees from various industry types participated in the study, we examined whether industry type was related to the core outcome variables. Specifically, we used the International Standard Industrial Classification of All Economic Activities (ISIC Revision 3.1; United Nations, 2002) for categorizing the participating organizations into seven industry types (manufacturing; retail; real estate, renting, and business activities; public administration and defense; education; health; and other community, social, and personal service activities) and included these categories as dummy variables in the analysis. Analysis revealed no significant main effects of industry types on well-being measures or psychological detachment. There were also no significant interaction effects between industry type and psychological detachment on well-being and no significant interaction effects between industry type and workload on psychological detachment. Therefore, we did not differentiate between various industry types in further analyses.
Similarly, because our sample included five selfemployed individuals and because employment status may be related to the core outcome variables, we included employment status as a dummy variable in our analysis $(0=$ employed, $1=$ self-employed $)$. There were no significant main effects of employment status on well-being measures or psychological detachment. Neither the interaction effects between employment status and workload measures on psychological detachment nor the interaction effects between employment status and psychological detachment on well-being were significant. There was also no evidence for any three-way interaction effect including employment status. Therefore, in further analyses we did not differentiate between employed and self-employed participants.

\section{Test of Hypotheses}

In Hypothesis 1, we predicted a negative effect of quantitative workload on psychological detachment from work. We used multilevel modeling for testing this hypothesis and compared nested models. Specifically, we compared three nested multilevel models: a null model, Model 1, and Model 2. In the null model, the intercept was the only predictor. In Model 1 , we entered demographic variables (gender, age, number of children; Level 2), action-state orientation (Level 2), and time spent on off-job time activities (Level 1) as control variables. In Model 2, we added chronic workload (Level 2) and day-specific workload (Level 1) as the core predictor variables of interest. We tested the improvement of each model above the previous one by computing the difference between the respective likelihood ratios. This difference follows a chi-square distribution (with degrees of freedom equal to the number of new parameters added to the model). Results are displayed in Table 3.

Analysis showed that Model 1, in which we entered the control variables, did not show an improvement over the null model (difference of $-2 \times \log =$ 13.105, $d f=9, n s)$. Model 2, which also included workload measures, fit the data better than did Model 1 (difference of $-2 \times \log =26.569, d f=4, p<$ $.01)$. High chronic time pressure and long day-specific work hours had negative effects on psychological detachment from work. Also, action-state orientation was significantly related to psychological detachment, with action-oriented individuals showing higher psychological detachment scores. Taken together, Hypothesis 1 was supported for chronic time pressure and day-specific work hours as predictor variables. 


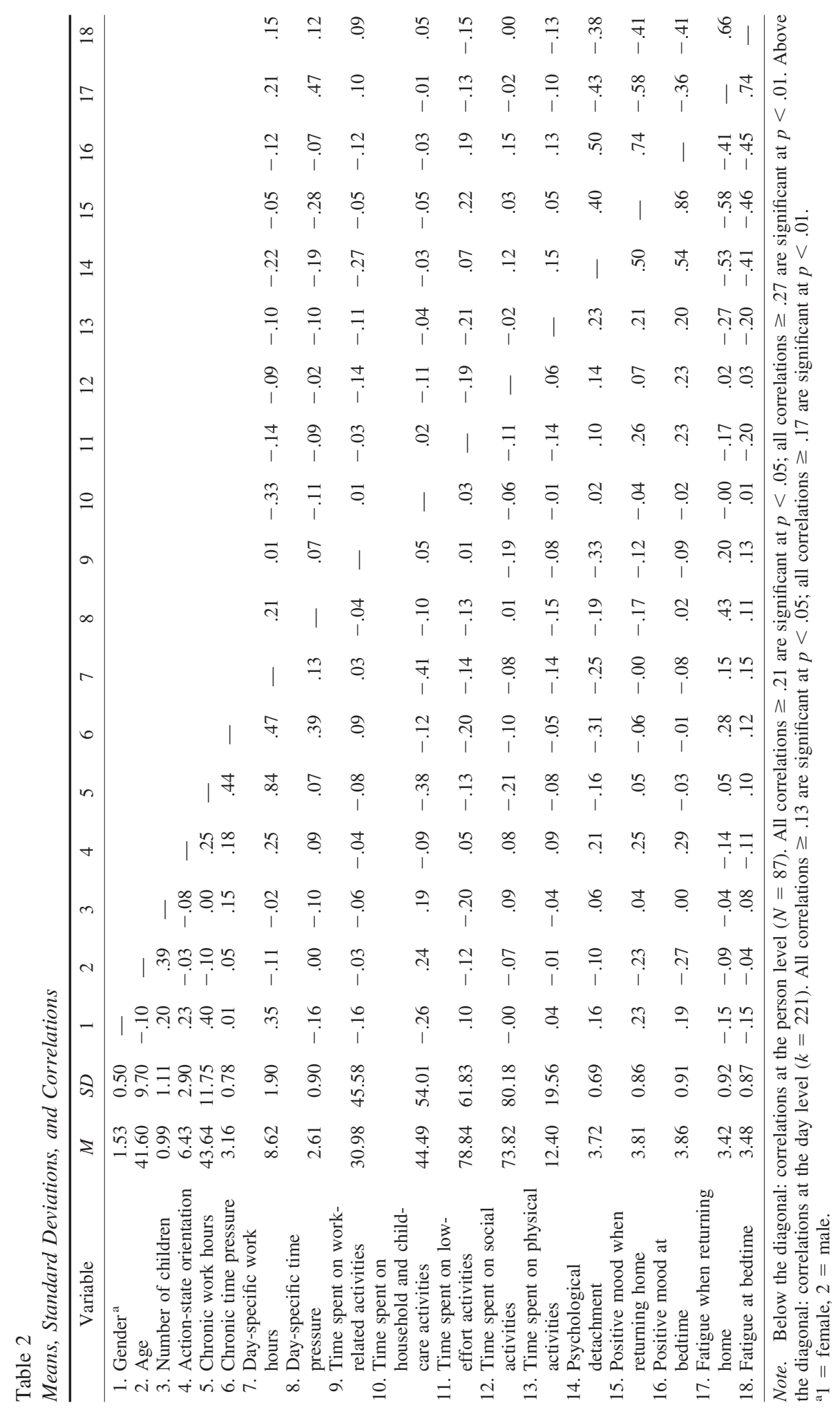


Table 3

Multilevel Estimates for Models Predicting Psychological Detachment From Quantitative Workload

\begin{tabular}{|c|c|c|c|c|c|c|c|c|c|}
\hline \multirow[b]{2}{*}{ Variable } & \multicolumn{3}{|c|}{ Null model ${ }^{\mathrm{a}}$} & \multicolumn{3}{|c|}{ Model $1^{\mathrm{b}}$} & \multicolumn{3}{|c|}{ Model $2^{\mathrm{c}}$} \\
\hline & Estimate & $S E$ & $t$ & Estimate & $S E$ & $t$ & Estimate & $S E$ & $t$ \\
\hline \multicolumn{10}{|l|}{ Fixed effects } \\
\hline Intercept & 3.7340 & 0.07363 & 50.713 & 3.7280 & 0.0701 & 53.212 & 3.3650 & 0.2385 & 14.109 \\
\hline Gender & & & & 0.0682 & 0.1514 & 0.451 & 0.1104 & 0.1561 & 0.707 \\
\hline Age & & & & -0.0086 & 0.0081 & -1.062 & -0.0097 & 0.0075 & -1.259 \\
\hline No. of children & & & & 0.0893 & 0.0729 & 1.225 & 0.1179 & 0.0691 & 1.705 \\
\hline Action-state orientation & & & & 0.0591 & 0.0253 & $2.337 *$ & 0.0802 & 0.0240 & $3.341 * *$ \\
\hline $\begin{array}{l}\text { Time spent on work-related } \\
\text { activities }\end{array}$ & & & & -0.0009 & 0.0010 & -0.979 & -0.0010 & 0.0009 & -1.027 \\
\hline Time spent on household & & & & & & & & & \\
\hline and child-care activities & & & & -0.0002 & 0.0008 & -0.208 & -0.0004 & 0.0007 & -0.616 \\
\hline $\begin{array}{l}\text { Time spent on low-effort } \\
\text { activities }\end{array}$ & & & & 0.0007 & 0.0008 & 0.793 & -0.0001 & 0.0008 & -0.147 \\
\hline Time spent on social & & & & & & & & & \\
\hline activities & & & & 0.0009 & 0.0006 & 1.489 & 0.0007 & 0.0006 & 1.169 \\
\hline Time spent on physical & & & & & & & & & \\
\hline activities & & & & 0.0020 & 0.0016 & 1.303 & 0.0015 & 0.0015 & 1.002 \\
\hline Chronic work hours & & & & & & & -0.0081 & 0.0071 & -1.146 \\
\hline Chronic time pressure & & & & & & & -0.2643 & 0.0979 & $-2.699 * *$ \\
\hline Day-specific work hours & & & & & & & -0.0920 & 0.0350 & $-2.631^{* *}$ \\
\hline \multirow[t]{2}{*}{ Day-specific time pressure } & & & & & & & -0.0854 & 0.0580 & -1.472 \\
\hline & $\begin{array}{l}\text { Intercept } \\
\text { variance }\end{array}$ & \multicolumn{2}{|c|}{$S E$} & $\begin{array}{l}\text { Intercept } \\
\text { variance }\end{array}$ & \multicolumn{2}{|r|}{$S E$} & $\begin{array}{l}\text { Intercept } \\
\text { variance }\end{array}$ & \multicolumn{2}{|r|}{$S E$} \\
\hline \multicolumn{10}{|l|}{ Random effects } \\
\hline Level 1 & 0.2813 & \multicolumn{2}{|c|}{0.0344} & 0.2723 & \multicolumn{2}{|c|}{0.0334} & 0.2474 & \multicolumn{2}{|c|}{0.0302} \\
\hline Level 2 & 0.3569 & \multicolumn{2}{|c|}{0.0727} & 0.3154 & \multicolumn{2}{|c|}{0.0656} & 0.2634 & \multicolumn{2}{|c|}{0.0564} \\
\hline
\end{tabular}

Note. $\quad N=87 . k=221$ days.

a $-2 \times \log (\mathrm{lh})=471.043 . \quad{ }^{\mathrm{b}}-2 \times \log (\mathrm{lh})=457.938$, Diff $-2 \times \log =13.105, d f=9 . \quad{ }^{\mathrm{c}}-2 \times \log (\operatorname{lh})=431.369$,

Diff $-2 \times \log =26.569 * * *, d f=4$.

$* p<.05 . \quad * * p<.01$. *** $p<.001$.

In Hypothesis 2, we proposed that psychological detachment has a positive effect on well-being at bedtime. Hypothesis 3 stated a moderator effect of day-specific workload on the relationship between psychological detachment and well-being at bedtime. Positive mood at bedtime and fatigue at bedtime were the dependent variables in these analyses. For each of these two dependent variables, we compared six nested multilevel models: a null model, Model 1, Model 2, Model 3, Model 4, and Model 5. In the null model the intercept was the only predictor. In Model 1, we entered demographic variables (Level 2) as control variables. In Model 2, we entered chronic (Level 2) and day-specific (Level 1) workload measures and well-being when coming home from work (Level 1). More specifically, to predict positive mood at bedtime, we entered positive mood when returning home from work as a control variable; to predict fatigue at bedtime, we entered fatigue when coming home from work as a control variable. In Model 3, we entered time spent on the five off-job activities as predictors (Level 1). In Model 4, we entered psychological detachment from work (Level 1) as the core predictor variable of interest in testing Hypothesis 2. A significant improvement of Model 4 over Model 3 would indicate support for Hypothesis 2. In Model 5, we entered the interaction terms between day-specific workload (Level 1) and psychological detachment (Level 1). A significant improvement of Model 5 over Model 4 would indicate support for Hypothesis 3 .

Table 4 summarizes the findings for positive mood at bedtime as the dependent variable. Model 1, which included demographic variables as control variables, showed a significant improvement over the null model (difference of $-2 \times \log =8.732, d f=3, p<$ $.05)$. Specifically, age was a significant predictor with older persons showing less positive mood at bedtime. In Model 2, we entered workload measures and positive mood when returning home from work. This model showed improvement over Model 1 (differ- 
Table 4

Multilevel Estimates for Models Predicting Positive Mood From Leisure Time Activities and Psychological Detachment

\begin{tabular}{|c|c|c|c|c|c|c|c|c|c|}
\hline \multirow[b]{2}{*}{ Variable } & \multicolumn{3}{|c|}{ Null model $^{\mathrm{a}}$} & \multicolumn{3}{|c|}{ Model $1^{\mathrm{b}}$} & \multicolumn{3}{|c|}{ Model $2^{\mathrm{c}}$} \\
\hline & Estimate & $S E$ & $t$ & Estimate & $S E$ & $t$ & Estimate & $S E$ & $t$ \\
\hline \multicolumn{10}{|l|}{ Fixed effects } \\
\hline Intercept & 3.8590 & 0.1002 & 38.513 & 3.5040 & 0.3183 & 11.008 & 3.3300 & 0.3404 & 9.783 \\
\hline Gender & & & & 0.2333 & 0.1986 & 1.175 & 0.3798 & 0.2202 & 1.725 \\
\hline Age & & & & -0.0275 & 0.0110 & $-2.510 *$ & -0.0277 & 0.0108 & $-2.561 *$ \\
\hline Number of children & & & & 0.0785 & 0.0978 & 0.802 & 0.0568 & 0.0984 & 0.577 \\
\hline \multicolumn{10}{|l|}{ Positive mood when } \\
\hline returning home & & & & & & & 0.2644 & 0.0775 & $3.412 * * *$ \\
\hline Chronic work hours & & & & & & & -0.0152 & 0.0102 & -1.487 \\
\hline Chronic time pressure & & & & & & & 0.0583 & 0.1400 & 0.417 \\
\hline \multicolumn{10}{|l|}{ Day-specific work } \\
\hline hours & & & & & & & -0.0381 & 0.0315 & 1.212 \\
\hline \multicolumn{10}{|l|}{ Day-specific time } \\
\hline pressure & & & & & & & -0.0737 & 0.0558 & 1.312 \\
\hline \multicolumn{10}{|l|}{$\begin{array}{l}\text { Time spent on work- } \\
\text { related activities }\end{array}$} \\
\hline \multicolumn{10}{|l|}{$\begin{array}{l}\text { Time spent on } \\
\text { household and child- } \\
\text { care activities }\end{array}$} \\
\hline \multicolumn{10}{|l|}{$\begin{array}{l}\text { Time spent on low- } \\
\text { effort activities }\end{array}$} \\
\hline \multicolumn{10}{|l|}{$\begin{array}{l}\text { Time spent on social } \\
\text { activities }\end{array}$} \\
\hline \multicolumn{10}{|l|}{$\begin{array}{l}\text { Time spent on physical } \\
\text { activities }\end{array}$} \\
\hline \multicolumn{10}{|l|}{$\begin{array}{r}\text { Psychological } \\
\text { detachment }\end{array}$} \\
\hline \multicolumn{10}{|l|}{ Day-Specific Work } \\
\hline \multicolumn{10}{|l|}{ Hours $\times$} \\
\hline \multicolumn{10}{|l|}{ Psychological } \\
\hline \multirow{2}{*}{\multicolumn{10}{|c|}{$\begin{array}{c}\text { Detachment } \\
\text { Day-Specific Time }\end{array}$}} \\
\hline & & & & & & & & & \\
\hline \multicolumn{10}{|l|}{ Pressure $\times$} \\
\hline \multicolumn{10}{|l|}{ Psychological } \\
\hline \multicolumn{10}{|l|}{ Detachment } \\
\hline & $\begin{array}{l}\text { Intercept } \\
\text { variance }\end{array}$ & & & $\begin{array}{l}\text { Intercept } \\
\text { variance }\end{array}$ & & SE & $\begin{array}{l}\text { Intercept } \\
\text { variance }\end{array}$ & & $S E$ \\
\hline \multicolumn{10}{|l|}{ Random effects } \\
\hline Level 1 & 0.2434 & & 98 & 0.2438 & & 299 & 0.2096 & & .0257 \\
\hline Level 2 & 0.7741 & 0.1 & & 0.6887 & & 1197 & 0.6795 & & .1158 \\
\hline
\end{tabular}

Note. $\quad N=87 . k=221$ days.

${ }^{\mathrm{a}}-2 \times \log (\mathrm{lh})=505.237 . \quad \mathrm{b}-2 \times \log (\mathrm{lh})=496.506$, Diff $-2 \times \log =8.731^{*}, d f=3 . \quad{ }^{\mathrm{c}}-2 \times \log (\operatorname{lh})=473.635$, Diff $-2 \times \log =22.871^{* * *}, d f=5 . \quad{ }^{\mathrm{d}}-2 \times \log (\mathrm{h})=464.262$, Diff $-2 \times \log =9.373, d f=5 . \quad \mathrm{e}-2 \times \log (\mathrm{lh})=$ 448.667, Diff $-2 \times \log =15.595^{* * *}, d f=1 .{ }^{\mathrm{f}}-2 \times \log (\mathrm{lh})=445.329$, Diff $-2 \times \log =3.338, d f=2$.

$* p<.05$. *** $p<.001$.

ence of $-2 \times \log =22.871, d f=5, p<.01)$. Positive mood when returning home was a strong predictor of positive mood at bedtime. In Model 3, we entered time spent on off-job activities as additional predictors. The improvement of Model 3 over
Model 2 was nonsignificant. However, inspection of the estimates of the several off-job activities revealed time spent on physical activities as a significant predictor of positive mood at bedtime. In Model 4, we added psychological detachment to the model. Model 


\begin{tabular}{|c|c|c|c|c|c|c|c|c|}
\hline \multicolumn{3}{|c|}{ Model $3^{\mathrm{d}}$} & \multicolumn{3}{|c|}{ Model $4^{\mathrm{e}}$} & \multicolumn{3}{|c|}{ Model $5^{f}$} \\
\hline Estimate & $S E$ & $t$ & Estimate & $S E$ & $t$ & Estimate & $S E$ & $t$ \\
\hline & & & 3.3050 & 0.3425 & 9.647 & 3.2630 & 0.3405 & 9.583 \\
\hline 3.3310 & 0.3430 & 9.711 & 0.3895 & 0.2215 & 1.758 & 0.4094 & 0.2198 & 1.861 \\
\hline 0.3789 & 0.2218 & 1.708 & -0.0279 & 0.0109 & $-2.561 *$ & -0.0275 & 0.0108 & $-2.546^{*}$ \\
\hline-0.0273 & 0.0109 & $-2.500 *$ & 0.0550 & 0.0990 & 0.555 & 0.0502 & 0.0981 & 0.512 \\
\hline 0.0555 & 0.0992 & 0.560 & 0.2652 & 0.0766 & $3.463 * * *$ & 0.2660 & 0.0768 & $3.465 * * *$ \\
\hline 0.3365 & 0.0789 & $4.267 * * *$ & -0.0160 & 0.0103 & -1.556 & -0.0164 & 0.0102 & -1.607 \\
\hline-0.0155 & 0.0102 & -1.512 & 0.0524 & 0.1408 & 0.372 & 0.0517 & 0.1395 & 0.371 \\
\hline 0.0570 & 0.1410 & 0.404 & -0.0060 & 0.0303 & -0.199 & -0.0029 & 0.0306 & -0.094 \\
\hline-0.0341 & 0.0313 & -1.090 & -0.0345 & 0.0532 & -0.649 & -0.0229 & 0.0533 & -0.430 \\
\hline-0.0454 & 0.0562 & -0.808 & -0.0010 & 0.0008 & -1.204 & -0.0011 & 0.0008 & 1.287 \\
\hline-0.0014 & 0.0009 & -1.592 & 0.0004 & 0.0006 & 0.583 & 0.0003 & 0.0006 & 0.524 \\
\hline 0.0002 & 0.0006 & 0.323 & 0.0003 & 0.0007 & 0.449 & 0.0004 & 0.0007 & 0.551 \\
\hline 0.0004 & 0.0007 & 0.514 & 0.0005 & 0.0005 & 0.982 & 0.0005 & 0.0005 & 0.947 \\
\hline 0.0008 & 0.0005 & 1.474 & 0.0026 & 0.0013 & $2.010^{*}$ & 0.0026 & 0.0013 & $2.043^{*}$ \\
\hline \multirow[t]{3}{*}{0.0032} & 0.0014 & $2.364 *$ & 0.3028 & 0.0746 & $4.062 * * *$ & 0.3318 & 0.0760 & 4.372 *** \\
\hline & & & & & & -0.0014 & 0.0963 & -0.014 \\
\hline & & & & & & -0.2662 & 0.1637 & -1.626 \\
\hline $\begin{array}{l}\text { Intercept } \\
\text { variance }\end{array}$ & \multicolumn{2}{|r|}{$S E$} & $\begin{array}{l}\text { Intercept } \\
\text { variance }\end{array}$ & \multicolumn{2}{|r|}{$S E$} & $\begin{array}{l}\text { Intercept } \\
\text { variance }\end{array}$ & \multicolumn{2}{|r|}{$S E$} \\
\hline 0.1936 & \multicolumn{2}{|c|}{0.0237} & 0.1726 & \multicolumn{2}{|c|}{0.0211} & 0.1704 & \multicolumn{2}{|c|}{0.0208} \\
\hline 0.6973 & \multicolumn{2}{|c|}{0.1181} & 0.7040 & \multicolumn{2}{|c|}{0.1177} & 0.6905 & \multicolumn{2}{|c|}{0.1156} \\
\hline
\end{tabular}

4 showed a significant improvement over Model 3 (difference of $-2 \times \log =15.595, d f=1, p<.01$ ). The estimate of psychological detachment was highly significant, indicating that psychological detachment contributed significantly to the prediction of positive mood at bedtime- beyond the effects of positive mood when returning home from work and beyond the effect of time spent on specific off-job activities. In Model 5, we entered the interaction terms between day-specific workload and psychological detach- 
Table 5

Multilevel Estimates for Models Predicting Fatigue From Leisure Time Activities and Psychological Detachment

\begin{tabular}{|c|c|c|c|c|c|c|c|c|c|}
\hline \multirow[b]{2}{*}{ Variable } & \multicolumn{3}{|c|}{ Null Model ${ }^{\mathrm{a}}$} & \multicolumn{3}{|c|}{ Model $1^{\mathrm{b}}$} & \multicolumn{3}{|c|}{ Model $2^{\mathrm{c}}$} \\
\hline & Estimate & $S E$ & $t$ & Estimate & $S E$ & $t$ & Estimate & $S E$ & $t$ \\
\hline \multicolumn{10}{|l|}{ Fixed effects } \\
\hline Intercept & 3.4800 & 0.09387 & 37.0725 & 3.9790 & 0.3074 & 12.944 & 4.1750 & 0.3294 & 12.675 \\
\hline Gender & & & & -0.3267 & 0.1916 & -1.705 & -0.4282 & 0.2131 & $-2.009 *$ \\
\hline Age & & & & -0.0096 & 0.0106 & -0.907 & -0.0103 & 0.0105 & -0.982 \\
\hline Number of children & & & & 0.1275 & 0.0947 & 1.346 & 0.1415 & 0.0953 & 1.484 \\
\hline \multirow{2}{*}{\multicolumn{10}{|c|}{$\begin{array}{l}\text { Fatigue when returning } \\
\text { home }\end{array}$}} \\
\hline & & & & & & & 0.4939 & 0.0815 & $6.059 * * *$ \\
\hline Chronic work hours & & & & & & & 0.0125 & 0.0099 & 1.261 \\
\hline Chronic time pressure & & & & & & & 0.0587 & 0.1353 & 0.434 \\
\hline \multicolumn{10}{|l|}{ Day-specific work } \\
\hline hours & & & & & & & 0.0060 & 0.0433 & 0.138 \\
\hline \multicolumn{10}{|l|}{ Day-specific time } \\
\hline pressure & & & & & & & -0.1120 & 0.0743 & -1.508 \\
\hline \multicolumn{10}{|l|}{$\begin{array}{l}\text { Time spent on work- } \\
\text { related activities }\end{array}$} \\
\hline \multicolumn{10}{|l|}{$\begin{array}{l}\text { household and child- } \\
\text { care activities }\end{array}$} \\
\hline \multicolumn{10}{|l|}{$\begin{array}{l}\text { Time spent on low- } \\
\text { effort activities }\end{array}$} \\
\hline \multicolumn{10}{|l|}{$\begin{array}{l}\text { Time spent on social } \\
\text { activities }\end{array}$} \\
\hline \multicolumn{10}{|l|}{$\begin{array}{l}\text { Time spent on physical } \\
\text { activities }\end{array}$} \\
\hline \multicolumn{10}{|l|}{$\begin{array}{r}\text { Psychological } \\
\text { detachment }\end{array}$} \\
\hline \multicolumn{10}{|l|}{ Day-Specific Work } \\
\hline \multicolumn{10}{|l|}{ Hours $\times$} \\
\hline \multicolumn{10}{|l|}{ Psychological } \\
\hline \multirow{2}{*}{\multicolumn{10}{|c|}{$\begin{array}{c}\text { Detachment } \\
\text { Day-Specific Time }\end{array}$}} \\
\hline & & & & & & & & & \\
\hline \multicolumn{10}{|l|}{ Pressure $x$} \\
\hline \multicolumn{10}{|l|}{ Psychological } \\
\hline \multicolumn{10}{|l|}{ Detachment } \\
\hline & $\begin{array}{l}\text { Intercept } \\
\text { variance }\end{array}$ & & $E$ & $\begin{array}{l}\text { Intercept } \\
\text { variance }\end{array}$ & & $E$ & $\begin{array}{l}\text { Intercept } \\
\text { variance }\end{array}$ & & $S E$ \\
\hline \multicolumn{10}{|l|}{ Random effects } \\
\hline Level 1 & 0.4888 & & 597 & 0.4881 & & 596 & 0.3700 & & .0452 \\
\hline Level 2 & 0.5673 & & 184 & 0.5368 & & 137 & 0.5639 & & .1096 \\
\hline
\end{tabular}

Note. $\quad N=87 . k=221$ days.

${ }^{\mathrm{a}}-2 \times \log (\mathrm{lh})=587.368 .{ }^{\mathrm{b}}-2 \times \log (\mathrm{lh})=583.602$, Diff $-2 \times \log =3.766, d f=3 .{ }^{\mathrm{c}}-2 \times \log (\operatorname{lh})=543.970$, Diff $-2 \times \log =39.632 * * *, d f=5 . \quad{ }^{\mathrm{d}}-2 \times \log (\mathrm{lh})=539.081$, Diff $-2 \times \log =4.889, d f=5 .^{\mathrm{e}}-2 \times \log (\operatorname{lh})=534.560$, Diff $-2 \times \log =4.521^{*}, d f=1 .{ }^{\mathrm{f}}-2 \times \log (\mathrm{lh})=528.478$, Diff $-2 \times \log =6.082^{*}, d f=2$.

$* p<.05$. *** $p<.001$.

ment. This model did not result in any improvement of model fit (difference of $-2 \times \log =3.338, d f=$ $2, n s)$. Taken together, for positive mood as dependent variable, our data show support for Hypothesis 2 but not for Hypothesis 3.
Table 5 shows the results for fatigue at bedtime as the dependent variable. Model 1, which included demographic variables as predictors, showed no significant improvement over the null model. In Model 2 , we added chronic and day-specific workload and 


\begin{tabular}{|c|c|c|c|c|c|c|c|c|}
\hline \multicolumn{3}{|c|}{ Model $3^{\mathrm{d}}$} & \multicolumn{3}{|c|}{ Model $4^{\mathrm{e}}$} & \multicolumn{3}{|c|}{ Model $5^{f}$} \\
\hline Estimate & $S E$ & $t$ & Estimate & $S E$ & $t$ & Estimate & $S E$ & $t$ \\
\hline & & & 4.2100 & 0.3305 & 12.738 & 4.1500 & 0.3369 & 12.318 \\
\hline 4.1870 & 0.3292 & 12.719 & -0.4441 & 0.2137 & $-2.078 *$ & -0.4164 & -0.2172 & -1.917 \\
\hline-0.4333 & 0.2129 & $-2.035^{*}$ & -0.0099 & 0.0105 & -0.941 & -0.0092 & -0.0107 & -0.861 \\
\hline-0.0104 & 0.0105 & -0.990 & 0.1456 & 0.0956 & 1.523 & 0.1371 & 0.0970 & 1.414 \\
\hline 0.1448 & 0.0953 & 1.520 & 0.4699 & 0.0815 & $5.769 * * *$ & 0.4305 & 0.0807 & $5.335^{* * * *}$ \\
\hline 0.5028 & 0.0814 & $6.174 * * *$ & 0.0128 & 0.0099 & 1.287 & 0.0128 & 0.0101 & 1.262 \\
\hline 0.0122 & 0.0099 & 1.243 & 0.0654 & 0.1357 & 0.482 & 0.0624 & 0.1377 & 0.437 \\
\hline 0.0628 & 0.1352 & 0.465 & -0.0153 & 0.0436 & -0.352 & -0.0087 & -0.0428 & -0.203 \\
\hline-0.0012 & 0.0439 & -0.028 & -0.1314 & 0.0740 & -1.776 & -0.0996 & -0.0730 & -1.365 \\
\hline-0.1207 & 0.0752 & -1.604 & -0.0002 & 0.0011 & -0.201 & -0.0003 & -0.0011 & -0.280 \\
\hline-0.0000 & 0.0012 & -0.003 & 0.0008 & 0.0009 & 0.927 & 0.0008 & 0.0008 & 0.919 \\
\hline 0.0009 & 0.0009 & 1.045 & -0.0015 & 0.0010 & -1.532 & -0.0012 & -0.0010 & -1.254 \\
\hline-0.0016 & 0.0010 & -1.591 & 0.0001 & 0.0007 & 0.206 & 0.0002 & 0.0007 & 0.281 \\
\hline-0.0000 & 0.0007 & -0.009 & -0.0019 & 0.0018 & -1.026 & -0.0016 & -0.0018 & -0.929 \\
\hline \multirow[t]{3}{*}{-0.0023} & 0.0018 & -1.244 & -0.2223 & 0.1034 & $-2.150^{*}$ & -0.1755 & -0.1023 & -1.716 \\
\hline & & & & & & 0.0717 & 0.1266 & 0.566 \\
\hline & & & & & & -0.5349 & -0.2183 & $-2.450 *$ \\
\hline $\begin{array}{l}\text { Intercept } \\
\text { variance }\end{array}$ & & $S E$ & $\begin{array}{l}\text { Intercept } \\
\text { variance }\end{array}$ & & $S E$ & $\begin{array}{l}\text { Intercept } \\
\text { variance }\end{array}$ & & \\
\hline 0.3573 & & 0437 & 0.3438 & & .0420 & 0.3227 & & \\
\hline 0.5675 & & 1093 & 0.5781 & & .1101 & 0.6071 & & \\
\hline
\end{tabular}

fatigue when returning home as additional predictors. Model 2 showed a highly significant improvement over Model 1 (difference of $-2 \times \log =39.632$, $d f=5, p<.01)$. The estimate of fatigue when returning home from work was highly significant. In this model, the estimate of gender was also significant, with women showing more fatigue at bedtime. In Model 3, we entered variables referring to time spent on off-job activities. Model fit did not improve (difference of $-2 \times \log =4.889, d f=5, n s$ ), 
indicating that time spent on the several off-job activities had no effect on fatigue at bedtime. In Model 4, we added psychological detachment from work into the model. Model 4 fit the data better than did Model 3 (difference of $-2 \times \log =4.521, d f=1$, $p<.05)$. The estimate of psychological detachment from work was significant and showed a negative sign. Thus, the data supported Hypothesis 2 for fatigue as the dependent variable as well. Finally, in Model 5 we entered the interaction terms between day-specific workload and psychological detachment. Analysis showed an improved model fit (difference of $-2 \times \log =6.082, d f=2, p<.05$ ), with a significant interaction term between day-specific time pressure and psychological detachment.

To explore the pattern of this interaction effect further, we followed the procedure proposed by Aiken and West (1991) and divided our sample into two subgroups with low versus high time pressure. Because our moderator variable was a day-level variable, the units in our subgroups were days and not persons. Specifically, the low time pressure subgroup comprised all days with time pressure below the person-specific mean; the high time pressure subgroups comprised all days with time pressure above the person-specific mean. We performed separate multilevel analyses with simple slope tests for these two subgroups, with fatigue as the dependent variable and psychological detachment as the predictor variable. For days with low time pressure, the model that included psychological detachment did not show a better model fit than the model without psychological detachment (difference of $-2 \times \log =0.292, d f=1, n s$ ). The slope of psychological detachment was not significant $(\gamma=-0.1053, S E=0.1933, t=0.54, n s)$. For days with high time pressure, the model that included psychological detachment fit the data better than the model without psychological detachment (difference of $-2 \times \log =6.058, d f=1, p<$ $.05)$. The slope of psychological detachment yielded a negative sign, indicating that low psychological detachment was associated with a high level of fatigue ( $\gamma=-0.4927, S E=0.1700, t=$ $-2.89, p<.01)$. Figure 2 shows that on days with low time pressure, psychological detachment was not related to fatigue. However, on days with high time pressure, psychological detachment was negatively related to fatigue. Taken together, Hypothesis 3 was supported for fatigue as the dependent variable.
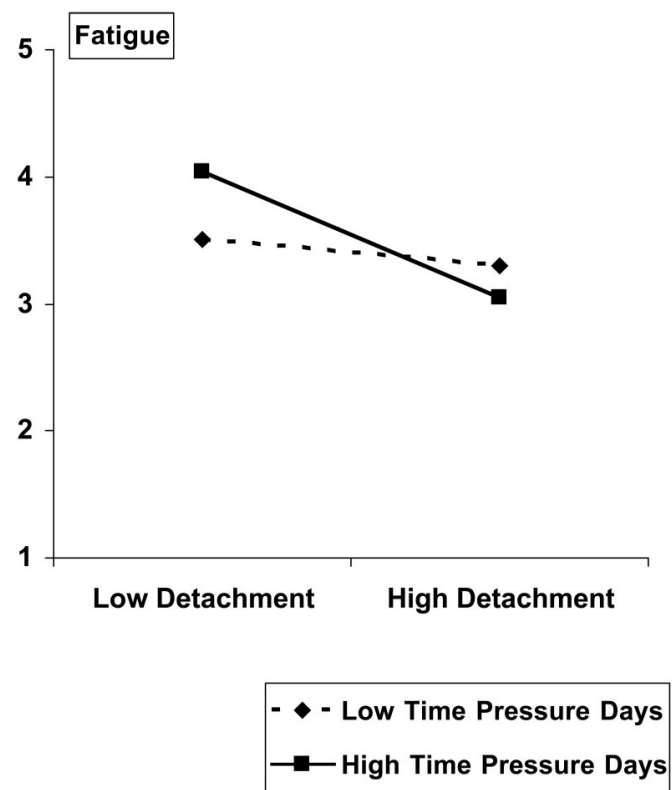

Figure 2. Interaction effect of time pressure and psychological detachment on fatigue.

\section{Discussion}

The results of this study point to a paradoxical situation. Previous research has shown that individuals who work long hours report a higher need for recovery after work (Sluiter, Van der Beek, \& FringsDresen, 1999). The results of the present study show that when confronted with high workload, individuals are less successful at detaching themselves psychologically from work. Thus, when workload is high, need for recovery increases-but at the same time this high need for recovery is less likely to be satisfied. In addition, our study shows that psychological detachment from work is positively associated with positive mood and low fatigue at bedtime. Moreover, after working days characterized by high time pressure, the effect of psychological detachment on fatigue was particularly strong.

\section{Predictors of Detachment}

Two of our four workload measures were found to be negatively related to psychological detachment. Thus, with increasing chronic time pressure and long day-specific work hours it is less likely that an individual detaches psychologically from work during 
evening hours. The finding that chronic but not dayspecific time pressure was associated with low psychological detachment suggests that it is not primarily the amount of time pressure that one has faced during the past working day that makes psychological detachment difficult but rather the anticipation that time pressure will continue during the working days to come. With respect to work hours, dayspecific work hours seem to be more relevant for psychological detachment than do chronic work hours. One may speculate that - up to a certain extent—individuals might adjust to long chronic work hours and organize their spare free time in a way such that they can benefit from it also when returning home from work late. However, individuals might be less prepared for long day-specific work hours and therefore might be less likely to psychologically detach from work during evening hours.

Our results parallel findings from studies that examined how individuals unwind from work. Frankenhaeuser (1981) and Meijman et al. (1992) reported that physiological stress indicators stayed elevated for a longer time and that it took employees longer to unwind physiologically after stressful working days than after less stressful days. In a recent study on overtime, a similar pattern of findings emerged, particularly for women holding poorly designed jobs (Rau \& Triemer, 2004). It might be that a high level of physiological arousal impedes psychological detachment from work and that, in turn, negatively affects well-being. An alternative interpretation would be that the inability to detach oneself from work hinders the unwinding process; that is, physiological arousal remains high because one continues to think about the past working day or anticipates the next day's workload. Here, more research is clearly needed.

Although the degree of psychological detachment differed across off-job time activities, time spent on specific off-job activities had no effect on overall psychological detachment. It might be that the categories of off-job activities used in this study were too broad. For example, the question of how much time one spends on household or low-effort activities as a whole might not be as relevant as some more specific types of household or low-effort activities that foster psychological detachment and others that hinder it. In addition, some types of off-job activities might include deliberate preoccupation with job-related thoughts (e.g., when meeting friends and talking with them about work). In addition, it might be that there is not a set of off-job activities that increases psychological detachment in all persons but that different activities are useful for different persons. For example, one person might best detach by doing sports, whereas another detaches when concentrating on household chores.

Our findings imply that just adding "free hours" in the late evening does not help in detaching psychologically from work. It might be that after having worked long hours, particularly under time pressure, one is perhaps already too fatigued to benefit from free hours and off-job activities. One might speculate that psychological detachment requires self-regulation, for example, a deliberate effort to stop jobrelated thoughts. Research has shown that self-regulation suffers under fatigue (Baumeister, Bratslavsky, Muraven, \& Tice, 1998). Thus, psychological detachment would be impaired in a situation in which self-regulation is required but not fully available because of preceding workload.

\section{Psychological Detachment as a Predictor of Positive Mood and Low Fatigue}

Analyses showed that psychological detachment from work during evening hours was positively related to positive mood and negatively related to fatigue at bedtime. These effects existed beyond the strong effects of positive mood and fatigue when returning home from work. Our findings suggest that it is not the mere physical distance to one's workplace that is important for recovery after work; rather, psychological detachment seems to be crucial. Our study adds to Etzion et al.'s (1998) research on detachment during longer respites by showing that short-term psychological detachment during normal work weeks plays a role in experiencing positive mood and low fatigue.

Analysis further revealed an interaction effect between day-specific time pressure and psychological detachment on fatigue. After working days characterized with high time pressure, psychological detachment from work during evening hours showed a strong negative relationship with fatigue at bedtime. After working days with low time pressure, psychological detachment was not related to fatigue. This finding implies that psychological detachment is particularly important after high time pressure days. If one is not able to psychologically detach from work after such working days, fatigue increases substantially.

The finding that day-specific time pressure moderated the relationship between psychological detachment and fatigue but not the relationship between 
psychological detachment and positive mood warrants attention. This pattern of findings suggests that thinking about work after high time pressure days is fatiguing because job-related thoughts might refer to a stress-relevant content, which further draws on one's resources. After days with low time pressure, job-related thoughts might not necessarily imply a stressful content and, therefore, they do not foster the fatigue process. Nevertheless, job-related thoughts during the evening after low time pressure days are also negatively related to positive mood. It might be that thinking about the job during evening hours does not meet individuals' expectations about a free evening and therefore individuals may regard low detachment as a negative experience that affects their mood. In addition, it might be that low detachment also negatively impacts the quality of social interactions during the evening and, as a consequence, positive mood suffers.

Unlike day-specific time pressure, day-specific long work hours did not moderate the relationship between psychological detachment and fatigue. Thus, although day-specific long work hours were negatively associated with psychological detachment, low detachment after long work days was not more detrimental to one's well-being than it was after shorter work days. It might be that although thinking about work in the evening is less frequent after shorter work days, it is not necessarily less stressful-as opposed to thinking about work after relatively relaxed, low time pressure days. Therefore, short working hours do not attenuate the relationship between psychological detachment and fatigue.

Our study showed that low psychological detachment from work during evening hours was related to poor well-being at bedtime. However, it must not be taken for granted that low detachment is always negatively related to well-being. In addition to the interaction effect found in the present study, one might argue that there are even days when low detachment is positively related to well-being. For example, after having successfully accomplished a major project or having received highly positive feedback from one's supervisor or an important client, continuous thinking about work may boost one's positive mood. Thus, the content of work-related thought might be crucial. A recent study on recovery during weekends showed that employees who reflected about their work in a positive way during the weekend experienced less exhaustion and less disengagement after returning to work (Fritz \& Sonnentag, 2005). In addition, when one is faced with a highly stressful situation at home, high psychological de- tachment from work may impede one's well-being, because work-related thoughts might help to stabilize well-being.

Furthermore, one might speculate that there are also individual differences in the degree to which persons experience job-related thoughts during offjob time as stressful. It might be that individuals high in job involvement even enjoy thinking about their work during off-job time. For these individuals, the relationship between psychological detachment during evening hours and well-being will be weaker than for individuals low in job involvement. Thus, future research on psychological detachment should pay more attention to situational factors and individual difference variables.

One might argue that positive mood and fatigue at bedtime are influenced by an individual's level of dispositional affect and not by day-specific psychological detachment. Although we did not control for dispositional affect in our analyses, we believe that it is unlikely that our findings can be primarily accounted for by dispositional affect. When predicting positive mood and fatigue at bedtime we included the respective affective measures assessed after work in the analyses. Dispositional affect should be already reflected in these after-work measures and therefore should not be a core explanatory variable for the relationship between psychological detachment and positive mood and fatigue at bedtime.

\section{Other Predictors of Positive Mood and Fatigue}

This study revealed a number of additional interesting findings. Analyses showed that men were less fatigued at bedtime than were women. This result corresponds to the observation that women react more negatively to stressful situations (Kivimäki et al., 1997). This finding is also in line with a totalworkload interpretation claiming that women face a higher total workload, including household and child-care duties, which makes it more difficult to recover during evening hours (Mardberg, Lundberg, \& Frankenhaeuser, 1991). In the present study women spent more time on household and child-care activities, $t(85)=2.43, p<.05$; however, time spent on household activities did not predict fatigue. Thus, it is not the mere amount of time women spent on household and child-care activities that contributes to an increase in fatigue. However, it could be that women spend more time on the more demanding types of household tasks or experience a higher re- 
sponsibility for household and child-care activities that increase fatigue (cf. Barnett \& Gareis, 2002).

Time spent on physical activities was positively associated with positive mood at bedtime. This finding is in line with a large body of research on the positive effect of sports on well-being (Byrne \& Byrne, 1993). It is interesting to note that this effect refers not only to differences between persons but also to variations within persons; that is, individuals feel better on days in which they spent more time on sports than they do on average. Despite the beneficial effect of physical activities on positive mood, physical activities did not decrease fatigue. This finding might be explained by the fact that physical activities are physically fatiguing. Maybe potentially positive effects on mental fatigue were counteracted by an increase in physical fatigue. Future studies should differentiate between mental and physical fatigue when examining the effects of physical activities.

\section{Limitations}

Some limitations of this study should be noted. First, the study relied on self-report data, and therefore a common method bias cannot be ruled out completely. However, we gathered data with two different instruments (questionnaire and daily survey) and assessed our study variables at different levels of specificity and detail. For example, we measured positive mood and fatigue with a set of rather global items, whereas we assessed psychological detachment at the level of each specific activity and later averaged these specific scores into an overall psychological detachment measure. In addition, work hours are rather objective measures of workload and are not easily influenced by response bias (Frese \& Zapf, 1988). Nevertheless, it is desirable that future research uses measures other than pure self-report data when examining the relationships between work overload, psychological detachment, and well-being. Asking participants' spouses about their partners' psychological detachment would be one option.

Second, although we provided detailed instructions about when to complete the daily survey, we cannot be completely sure that our participants always complied with the instructions and answered all items at the requested points in time. However, because there were data missing at points when some participants skipped some measurement points, we are rather confident that participants did not fake their survey completion times. Nevertheless, to overcome this problem in future studies, researchers could use handheld computers for data collection that allow for the recording of time stamps when specific items are completed.

Third, our participants were highly educated and on average held intellectually demanding jobs. Thus, it remains an open question for future research whether the relationship between high workload and low detachment is specific for individuals in intellectually demanding jobs or whether it generalizes beyond these work settings. Nevertheless, participants came from different organizations and had diverse professional backgrounds. Therefore, our findings are not limited to one specific organization or profession but probably generalize to a broader range of organizations and professions.

\section{Implications for Research and Practice}

Our study has some implications for future research and practice. In this study, we examined shortterm effects of psychological detachment that became evident within a few hours. Future research should address longer term outcomes of psychological detachment during evening hours. For example, one might hypothesize that psychological detachment from work during evening not only improves wellbeing on the same day but helps to protect individual health and well-being in the long run. Longitudinal studies over longer time periods are needed. In addition, it would be interesting to investigate whether psychological detachment from work during evening hours has an effect on job-related behavior, particularly job performance, during the next day.

This study indicates that high workload is detrimental for psychological detachment. Although desirable, workload cannot always be reduced. Therefore, it is an important question for future research to examine how individuals can detach psychologically from their work, particularly during periods of high workload. Eden (2001) pointed out that self-efficacy might play an important role when predicting successful recovery. One can speculate that recovery self-efficacy, that is, one's belief in the ability to recover from work during evening hours, is a crucial factor in order for one to fully benefit from off-job experiences.

With respect to practical implications, our findings underscore the importance of psychological detachment for improving positive mood and reducing fatigue during evening hours. Therefore, individuals should be encouraged to switch off mentally from work when leaving their working place and arriving at home. Potentially helpful strategies might include 
deliberate relaxation exercises (Carlson \& Holye, 1993) or the initiation of flow experiences during leisure time activities (Csikszentmihalyi \& LeFevre, 1989). The most important starting point for any intervention, however, is probably the reduction of workload. It would be particularly relevant to avoid chronic time pressure and to refrain from long dayspecific working days. Such a reduction of workload will not only decrease an individual's need for recovery (Sluiter et al., 1999) but also have a positive impact on the recovery process by making psychological detachment from work more likely. Overall, psychological detachment from work during evening hours may be one important factor that contributes to individuals' work-life balance.

\section{References}

Adams, G. A., King, L. A., \& King, D. W. (1996). Relationships of job and family involvement, family social support, and work-family conflict with job and life satisfaction. Journal of Applied Psychology, 81, 411-420.

Aiken, L. S., \& West, S. G. (1991). Multiple regression: Testing and interpreting interactions. Newbury Park, CA: Sage.

Apenburg, E. (1986). Befindlichkeitsbeschreibung als Methode der Beanspruchungsmessung [State description as a method for measuring stress]. Psychologie und Praxis, 30, 3-14.

Barnett, R. C., \& Gareis, K. C. (2002). Full-time and reduced-hours work schedules and marital quality: A study of female physicians with young children. Work \& Occupations, 29, 364-379.

Baumeister, R. F., Bratslavsky, E., Muraven, M., \& Tice, D. M. (1998). Ego depletion: Is the active self a limited resource? Journal of Personality and Social Psychology, 74, 1252-1265.

Bryk, A. S., \& Raudenbush, S. W. (1992). Hierarchical linear models: Application and data analysis methods. Newbury Park, CA: Sage.

Byrne, A., \& Byrne, D. G. (1993). The effect of exercise on depression, anxiety and other mood states: A review. Journal of Psychosomatic Research, 37, 565-574.

Carayon, P. (1993). A longitudinal test of Karasek's job strain model among office workers. Work and Stress, 7, 299-314

Carlson, C. R., \& Holye, R. H. (1993). Efficacy of abbreviated progressive muscle relaxation training: A quantitative review of behavioral medicine research. Journal of Consulting and Clinical Psychology, 61, 1059-1067.

Craig, A., \& Cooper, R. E. (1992). Symptoms of acute and chronic fatigue. In A. P. Smith \& D. M. Jones (Eds.), Handbook of human performance (Vol. 3, pp. 289-339). London: Academic Press.

Csikszentmihalyi, M., \& LeFevre, J. (1989). Optimal experience in work and leisure. Journal of Personality and Social Psychology, 56, 815-822.

deCroon, E. M., Sluiter, J. K., Blonk, R. W. B., Broersen, J. P. J., \& Frings-Dresen, M. H. W. (2004). Stressful work, psychological job strain, and turnover: A 2-year prospective cohort study of truck drivers. Journal of Applied Psychology, 89, 442-454.

Eden, D. (2001). Vacations and other respites: Studying stress on and off the job. In C. L. Cooper \& I. T. Robertson (Eds.), International review of industrial and organizational psychology (pp. 121-146). Chichester, England: Wiley.

Elfering, A., Grebner, S., Semmer, N. K., \& Gerber, H. (2002). Time control, catecholamines and back pain among young nurses. Scandinavian Journal of Work Environment and Health, 28, 386-393.

Etzion, D., Eden, D., \& Lapidot, Y. (1998). Relief from job stressors and burnout: Reserve service as a respite. Journal of Applied Psychology, 83, 577-585.

Frankenhaeuser, M. (1981). Coping with stress at work. International Journal of Health Services, 11, 491-510.

Frese, M. (1985). Stress at work and psychosomatic complaints: A causal interpretation. Journal of Applied Psychology, 70, 314-328.

Frese, M. (1999). Social support as a moderator of the relationship between work stressors and psychological dysfunctioning: A longitudinal study with objective measures. Journal of Occupational Health Psychology, 4, 179-192.

Frese, M., \& Zapf, D. (1988). Methodological issues in the study of work stress: Objective vs. subjective measurement and the question of longitudinal studies. In C. L. Cooper \& R. Payne (Eds.), Causes, coping, and consequences of stress at work (pp. 375-411). New York: Wiley.

Fritz, C., \& Sonnentag, S. (in press). Recovery, well-being, and performance-related outcomes: The role of work load and specific vacation experiences. Journal of Applied Psychology.

Fritz, C., \& Sonnentag, S. (2005). Recovery, health, and job performance: Effects of weekend experiences. Journal of Occupational Health Psychology, 3, 187-199.

Ganster, D. C., Fox, M. L., \& Dwyer, D. J. (2001). Explaining employees' health care costs: A prospective examination of stressful job demands, personal control, and physiological reactivity. Journal of Applied Psychology, 86, 954-964.

Ganster, D. C., \& Schaubroeck, J. (1991). Work stress and employee health. Journal of Management, 17, 235-271.

Garst, H., Frese, M., \& Molenaar, P. C. M. (2000). The temporal factor of change in stressor-strain relationships: A growth curve model on a longitudinal study in East Germany. Journal of Applied Psychology, 85, 417-438.

Geurts, S. A. E., \& Demerouti, E. (2003). Work/non-work interface: A review of theories and findings. In M. J. Schabraqc, J. A. M. Winnubst, \& C. L. Cooper (Eds.), The handbook of work and health psychology (pp. 279312). Chichester, United Kingdom: Wiley.

Geurts, S. A. E., Kompier, M. A. J., Roxburgh, S., \& Houtman, I. L. D. (2003). Does work-home interference mediate the relationship between workload and wellbeing? A multi-sample analysis. Journal of Vocational Behavior, 63, 532-559.

Hart, P. M. (1999). Predicting employee life satisfaction: A coherent model of personality, work, and nonwork experiences, and domain satisfactions. Journal of Applied Psychology, 84, 564-584.

Kahn, R. L., \& Byosiere, P. (1992). Stress in organizations. In M. D. Dunnette \& L. M. Hough (Eds.), Handbook of 
industrial and organizational psychology (2nd ed., Vol 3, pp. 571-650). Palo Alto, CA: Consulting Psychologists Press.

Kivimäki, M., Vahtera, J., Thomson, L., Griffiths, A., Cox, T., \& Pentti, J. (1997). Psychosocial factors predicting employee sickness absence during economic decline. Journal of Applied Psychology, 82, 858-872.

Krueger, G. P. (1989). Sustained work, fatigue, sleep loss and performance: A review of the issues. Work \& Stress, 3, 129-141.

Kuhl, J. (1990). Der Fragebogen zur Erfassung von Handlungskontrolle nach Erfolg, Mißerfolg und prospektiv HAKEMP 90 [Questionnaire for assessing action control after success, failure, and prospectively HAKEMP 90] Osnabrück, Germany: University of Osnabrück.

Kuhl, J. (1994a). Action versus state orientation: Psychometric properties of the action control scale (ACS-90). In J. Kuhl \& J. Beckmann (Eds.), Volition and personality: Action versus state orientation (pp. 47-59). Seattle, WA: Hogrefe \& Huber.

Kuhl, J. (1994b). A theory of action and state orientations. In J. Kuhl \& J. Beckmann (Eds.), Volition and personality: Action versus state orientation (pp. 9-46). Seattle, WA: Hogrefe \& Huber.

Lounsbury, J. W., \& Hoopes, L. L. (1986). A vacation from work: Changes in work and nonwork outcomes. Journal of Applied Psychology, 71, 392-401.

Lundberg, U., \& Lindfors, P. (2002). Psychophysiological reactions to telework in female and male white-collar workers. Journal of Occupational Health Psychology, 7, 354-364.

Major, V. S., Klein, K. J., \& Ehrhart, M. G. (2002). Work time, work interference with family, and psychological distress. Journal of Applied Psychology, 87, 427-436.

Mardberg, B., Lundberg, U., \& Frankenhaeuser, M. (1991). The total workload of parents employed in white-collar jobs: Construction of a questionnaire and a scoring system. Scandinavian Journal of Psychology, 32, 233-239.

Martin, E., \& Weber, A. (1976). Wirkungen eintönig-repetitiver Tätigkeiten auf das subjektive Befinden und die Flimmerverschmelzungs-Frequenz [The effects of monotonous repetitive activities on subjective condition and on the critical fusion frequency]. Zeitschrift für Arbeitswissenschaft, 30, 183-187.

McEwen, B. S. (1998). Protective and damaging effects of stress mediators. New England Journal of Medicine, 338, $171-179$

Meijman, T. F., \& Mulder, G. (1998). Psychological aspects of workload. In P. J. D. Drenth \& H. Thierry (Eds.), Handbook of work and organizational psychology: Vol. 2. Work psychology (pp. 5-33). Hove, England: Psychology Press.

Meijman, T. F., Mulder, G., Van Dormolen, M., \& Cremer, R. (1992). Workload of driving examiners: A psychophysiological field study. In H. Kragt (Ed.), Enhancing industrial performances (pp. 245-260). London: Taylor \& Francis.

Mohr, G. (1986). Die Erfassung psychischer Befindensbeeinträchtigungen bei Arbeitern [Assessment of psychological stress effects in industrial workers]. Frankfurt/M., Germany: Lang.

Morin, C. M., Rodrigue, S., \& Ivers, H. (2003). Role of stress, arousal, and coping skills in primary insomnia. Psychosomatic Medicine, 65, 259-267.
Morrow, J., \& Nolen-Hoeksema, S. (1990). Effects of response to depression on the remediation of depressive affect. Journal of Personality and Social Psychology, 58, $519-527$

Nitsch, J. R. (1976). Die Eigenzustandsskala (EZ-Skala)Ein Verfahren zur hierarchisch-mehrdimensionalen Befindlichkeitsskalierung [Own state scale-An instrument for hierarchical-multidimensional state scaling]. In J. R. Nitsch \& I. Udris (Eds.), Beanspruchung im Sport. Bad Homburg, Germany: Limpert.

Rasbash, J., \& Woodhouse, G. (1996). MLn. London: University of London, Institute of Education.

Rau, R., \& Triemer, A. (2004). Overtime work as related to blood pressure and mood during work, leisure and night time. Social Indicators Research, 67, 51-73.

Roger, D., \& Najarian, B. (1998). The relationship between emotional rumination and cortisol secretion under stress. Personality and Individual Differences, 24, 531-538.

Rothbard, N. P. (2001). Enriching or depleting? The dynamics of engagement in work and family roles. Administrative Science Quarterly, 46, 655-684.

Russell, J. A. (1980). A circumplex model of affect. Journal of Personality and Social Psychology, 39, 1161-1178.

Semmer, N. (1984). Streßbezogene Tätigkeitsanalyse [Stress-related job analysis]. Weinheim, Germany: Beltz. Semmer, N., Zapf, D., \& Greif, S. (1996). "Shared job strain": A new approach for assessing the validity of job stress measurements. Journal of Occupational and Organizational Psychology, 69, 293-310.

Sluiter, J. K., Van der Beek, A. J., \& Frings-Dresen, M. H. W. (1999). The influence of work characteristics on the need for recovery and experienced health: A study on coach drivers. Ergonomics, 42, 573-583.

Snijders, T. A. B., \& Bosker, R. J. (1999). Multilevel analysis. An introduction to basic and advanced multilevel modeling. London: Sage.

Sonnentag, S. (2001). Work, recovery activities, and individual well-being: A diary study. Journal of Occupational Health Psychology, 6, 196-210.

Sonnentag, S. (2003). Recovery, work engagement, and proactive behavior: A new look at the interface between nonwork and work. Journal of Applied Psychology, 88, 518-528.

Sonnentag, S., \& Frese, M. (2003). Stress in organizations. In W. C. Borman, D. R. Ilgen, \& R. J. Klimoski (Eds.), Comprehensive handbook of psychology: Vol. 12. Industrial and organizational psychology (pp. 453-491). New York: Wiley.

Sparks, K., Cooper, C., Fried, Y., \& Shirom, A. (1997). The effects of hours of work on health: A meta-analytic review. Journal of Occupational and Organizational Psychology, 70, 391-408.

Spector, P. E., Chen, P. Y., \& O'Connell, B. J. (2000). A longitudinal study of relations between job stressors and job strains while controlling for prior negative affectivity and strains. Journal of Applied Psychology, 85, 211-218.

Teuchmann, K., Totterdell, P., \& Parker, S. K. (1999). Rushed, unhappy, and drained: An experience sampling study of relations between time pressure, perceived control, mood, and emotional exhaustion in a group of accountants. Journal of Occupational Health Psychology, 4, 37-54.

Thayer, R. E., Newman, J. R., \& McClain, T. M. (1994). Self-regulation of mood: Strategies for changing a bad 
mood, raising energy, and reducing tension. Journal of Personality and Social Psychology, 67, 910-925.

Totterdell, P., \& Parkinson, B. (1999). Use and effectiveness of self-regulation strategies for improving mood in a group of trainee teachers. Journal of Occupational Health Psychology, 4, 219-232.

Totterdell, P., Spelten, E., Smith, L., Barton, J., \& Folkard, S. (1995). Recovery from work shifts: How long does it take? Journal of Applied Psychology, 80, 43-57.

Udris, I., \& Barth, H. (1976). Beanspruchungsaspekte der Arbeitsorganisation im Bürobereich [Workload aspects of work organization in offices]. Zeitschrift für Arbeitswissenschaft, 30, 87-91.

United Nations. (2002). International Standard Industrial Classification of All Economic Activities. (ISIC Rev. 3.1) Retrieved July 30, 2003, from http://unstats.un.org/unsd/ cr/registry/regcst.asp?Cl $=17$

Van der Doef, M., \& Maes, S. (1999). The job demandcontrol (-support) model and psychological well-being: A review of 20 years of empirical research. Work \& Stress, 13, 87-114.
Watson, D., \& Tellegen, A. (1985). Toward a consensual structure of mood. Psychological Bulletin, 98, 219-235.

Westman, M., \& Eden, D. (1997). Effects of a respite from work on burnout: Vacation relief and fade-out. Journal of Applied Psychology, 82, 516-527.

Westman, M., \& Etzion, D. (2001). The impact of vacation and job stress on burnout and absenteeism. Psychology and Health, 16, 595-606.

Young, E. A., \& Nolen-Hoeksema, S. (2001). Effect of rumination on the salvia cortisol response to a social stressor. Psychoneuroenocrinology, 26, 319-329.

Zapf, D. (1993). Stress-oriented analysis of computerized office work. European Work and Organizational Psychologist, 3, 85-100. 